\title{
Mid-term results of completely portal robotic lobectomy for stage I \& II non-small cell lung cancer
}

\author{
Kingsfield Ong, Ali Akbar Fazuludeen, Aneez Dokeu Basheer Ahmed \\ Division of Thoracic Surgery, Department of General Surgery, Tan Tock Seng Hospital, Singapore, Singapore \\ Contributions: (I) Conception and design: All authors; (II) Administrative support: All authors; (III) Provision of study materials or patients: All \\ authors; (IV) Collection and assembly of data: All authors; (V) Data analysis and interpretation: All authors; (VI) Manuscript writing: All authors; (VII) \\ Final approval of manuscript: All authors. \\ Correspondence to: Mr. Aneez Dokeu Basheer Ahmed. Division of Thoracic Surgery, Department of General Surgery, Annex Building 1, Level 4, 11 \\ Jalan Tan Tock Seng, Singapore 308433, Singapore. Email: Dokeu@yahoo.com.
}

\begin{abstract}
Background: Minimally invasive robotic-assisted thoracic surgery is an increasingly popular platform for oncological thoracic resection. The aim of this study is to evaluate the feasibility of completely portal robotic lobectomy for patients with early non-small cell lung cancer (NSCLC), analysing the perioperative and midterm results.

Methods: This is a single-institution retrospective cohort study of consecutive patients who underwent completely portal robotic lobectomy for early stage NSCLC over a 53-month period.

Results: A total of 59 consecutive patients were included in this study. Median operative time was $155 \mathrm{~min}$ (range, 80-313 min). Conversion rate was 13.6\%. Median intensive care/high dependency unit stay, chest tube duration and length of hospital stay were 1 day (range, 0-4 days), 2 days (range, 1-20 days) and 4 days (range, 2-30 days) respectively; $98.2 \%$ of patients achieved R0 resection. Overall, 23.7\% had minor complications. There was no perioperative (30-day) mortality in this study. Final pathological staging distribution was $55.9 \%$ stage $1 \mathrm{~A}, 23.7 \%$ stage $1 \mathrm{~B}, 10.2 \%$ stage $2 \mathrm{~A}$ and $10.2 \%$ stage $2 \mathrm{~B}$; $23 \%$ were upstaged after pathological staging. Median follow-up was 33 months (range, 3-70 months). The 3-year overall survival and recurrence-free survival were 86.2\% (95\% CI, 72.0-96.8) and 69\% (95\% CI, 56.1-81.9) respectively. The 3 -year overall survival and recurrence free survival for stage 1 patients were $88.4 \%(95 \%$ CI, 77.4-99.4) and 75.6\% (95\% CI, 62.3-88.9) respectively.

Conclusions: By clearly defining completely portal robotic lobectomy, it is possible to delivery promising perioperative and mid-term results for early stage primary lung cancer, even in a geographical location that has yet to assimilate this technology.
\end{abstract}

Keywords: Non-small cell lung cancer (NSCLC); robotic lobectomy; surgery

Submitted May 27, 2020. Accepted for publication Sep 10, 2020.

doi: $10.21037 /$ jtd-20-1915

View this article at: http://dx.doi.org/10.21037/jtd-20-1915

\section{Introduction}

Pulmonary lobectomy remains the gold standard for resectable lung cancer (1). Advances in minimally invasive techniques have completely altered the landscape of thoracic surgery. Video-assisted thoracoscopic surgery (VATS) lobectomy has demonstrated distinct benefits, including shorter hospital stay, reduced pain, better postoperative lung function, lower rates of bleeding and transfusions and improved ease of commencing adjuvant chemotherapy $(2,3)$. Despite these advantages, slow adoption of VATS is surprising. Less than $50 \%$ of lobectomies for primary lung cancers in the United States utilise the VATS approach (4).

The revolution of robotic-assisted thoracic surgery has provided surgeons with high magnification imaging, ergonomic articulation of instruments (7 degrees of 
freedom), elimination of fine tremors, with a state-of-theart master-slave console system for enhanced operator comfort. Since early reports of successful robotic-assisted lobectomy in 2002 (5), it has become an increasingly popular platform for oncological thoracic resection, demonstrating respectable perioperative and long-term outcomes $(6,7)$.

In South East Asia, completely portal robotic lobectomy (CPRL4) is still in its early infancy and sparsely reported in the medical literature. The aim of this study is to evaluate the feasibility of completely portal robotic lobectomy (CPRL4) for patients with early stage non-small cell lung cancer (NSCLC), analysing the perioperative and mid-term results.

We present the following article in accordance with the STROBE reporting checklist (available at http://dx.doi. org/10.21037/jtd-20-1915).

\section{Methods}

\section{Study design}

This is a single-institution retrospective cohort study of consecutive patients who underwent CPRL4 for early stage NSCLC from June 2013-November 2017. This study was approved by the Domain Specific Review Board National Health Care Group (Singapore), with waiver of patient consent (Study Reference Number 2017/00762). The study was conducted in accordance with the Declaration of Helsinki (as revised in 2013). All procedures were carried out by a single surgeon at an academic and training institution in Singapore.

\section{Inclusion criteria}

Eligibility for curative R0 surgical lobectomy included biopsy-proven or highly suspected primary NSCLC lung without locally advanced extra-thoracic disease demonstrated on computed tomography (CT) of the thorax and full body positron emission tomography-CT (PETCT). Only subjects with NSCLC pathological stage I and stage II [ 7 th edition of American Joint Committee on Cancer Staging (8)] were enrolled in the study. Although the latest 8th edition of TNM staging has been effective worldwide since 2018, these patients were treated during the time when the 7 th edition of TNM staging was in effect. Hence, the 7th edition of TNM staging was used in this study. Small-cell lung cancers, carcinoid, metastatic or benign lesions and rare thoracic parenchymal malignancies were excluded. To minimise bias, robotic resection was offered to all patients who fulfilled the above criteria. Before the introduction of the robotic platform, this cohort of patients would have otherwise had undergone open or video assisted thoracoscopic lobectomy. Patient who underwent robotic segmentectomy and wedge resections were excluded from this study as well.

\section{Operative technique}

All patients underwent anatomical lobectomy with mediastinal lymph node dissection by CPRL4 technique as described by Cerfolio using the Xi Robot (da Vinci; Intuitive Surgical, Sunnyvale, California) (9). Paravertebral nerve block via paravertebral catheter or intravenous infusion of patient-controlled analgesia was employed for pain control. Post-operatively, patients were routinely admitted to the surgical high dependency unit.

\section{Data collection}

Preoperative, intraoperative and postoperative data were extracted from existing medical records. Conversion was defined by rib-spreading thoracotomy after docking of the robot. Major morbidity and complication were defined according to The Society of Thoracic Surgeons database's definitions. Upon discharge, all patients were reviewed at two weeks with chest X-ray followed by interval 6 monthly CT chest. If suspicious lesions $(>8 \mathrm{~mm})$ were found, PET/CT would be performed along with other relevant investigations. Overall survival and recurrence-free survival were recorded from date of operation to date of death or last trackable follow-up.

\section{Statistical method}

Continuous data was presented in frequencies and percentages, while categorical data was expressed in median and range. Overall survival and recurrence-free survival were analysed by using Kaplan-Meier method and compared by Log-rank test. All analyses were performed with SPSS statistical software version 25.

\section{Results}

A total of 59 consecutive patients were included in this study. Table 1 depicts the patient characteristic and co- 
Table 1 Patient characteristics

\begin{tabular}{|c|c|}
\hline Characteristics & $\mathrm{N}=59$ \\
\hline Age, median [range] & 68 [40-82] \\
\hline Gender (male:female) & 29:30 \\
\hline \multicolumn{2}{|l|}{ Smoking history, n (\%) } \\
\hline Non-smoker & $38(64.4)$ \\
\hline Ex-smoker & $14(23.7)$ \\
\hline Current-smoker & 7 (11.9) \\
\hline \multicolumn{2}{|l|}{ Co-morbidities, n (\%) } \\
\hline Hypertension & $36(61.0)$ \\
\hline Hyperlipidemia & $35(59.3)$ \\
\hline Diabetes & $15(25.4)$ \\
\hline Coronary artery disease & $12(20.3)$ \\
\hline Atrial fibrillation & $1(1.7)$ \\
\hline Cerebral vascular disease & $3(5.1)$ \\
\hline Chronic obstructive pulmonary disease & $2(3.4)$ \\
\hline Asthma & $6(10.2)$ \\
\hline Renal disease & $1(1.7)$ \\
\hline Thyroid disease & $6(10.2)$ \\
\hline Previous malignancy & $8(13.6)$ \\
\hline Rheumatologic diseases on steroids & $3(5.1)$ \\
\hline ASA, median [range] & $2[1-3]$ \\
\hline
\end{tabular}

morbidities. Table 2 reports the tumour characteristic and stage distribution. Table 3 shows the peri-operative variables. The median age was 68 years ( $40-82$ years). Comorbidities included hypertension $61 \%$, hyperlipidemia $59.3 \%$, diabetes $25.4 \%$, coronary artery disease $20.3 \%$, atrial fibrillation $1.7 \%$, cerebral vascular disease $5.1 \%$, chronic obstructive pulmonary disease $3.4 \%$, asthma $10.2 \%$, chronic renal disease $1.7 \%$, thyroid disease $10.2 \%$, previous malignancy $13.6 \%$ and rheumatologic diseases on steroids $5.1 \%$. Median operative time was $155 \mathrm{~min}$ (range, 80-313 min). Median ICU/HDU stay, chest tube duration and length of hospital stay were 1 day (range, 0-4 days), 2 days (range, 1-20 days) and 4 days (range, 2-30 days) respectively.

The conversion rate was $13.6 \%(\mathrm{~N}=8)$. Conversion case one was a right upper lobectomy with extensive calcified hilar lymphadenopathy and aberrant vessels supplying the right upper lobe. Conversion case two was a left lower
Table 2 Tumour characteristics and staging

\begin{tabular}{|c|c|}
\hline Variables & Number \\
\hline \multicolumn{2}{|l|}{ Location of tumour } \\
\hline Right:left & $34: 25$ \\
\hline Right upper lobe (\%) & 22/59 (37.3) \\
\hline Right middle lobe (\%) & $4 / 59(6.8)$ \\
\hline Right lower lobe (\%) & $12 / 59(20.3)$ \\
\hline Left upper lobe (\%) & $15 / 59(25.4)$ \\
\hline Left lower lobe (\%) & 10/59 (16.9) \\
\hline Tumour size on CT (cm), median [range] & $2.65[1-4.6]$ \\
\hline Tumour size on histology $(\mathrm{cm})$, median [range] & $2.5[0.9-7]$ \\
\hline \multicolumn{2}{|l|}{ Histological type (\%) } \\
\hline Adenocarcinoma & $51 / 59(86.4)$ \\
\hline Squamous cell carcinoma & $7 / 59(11.9)$ \\
\hline Adenosquamous carcinoma & $1 / 59(1.7)$ \\
\hline \multicolumn{2}{|l|}{ Pre-operative clinical staging (\%) } \\
\hline Stage $1 \mathrm{~A}$ & $38 / 56(67.9)$ \\
\hline Stage 1B & $13 / 56(23.2)$ \\
\hline Stage $2 \mathrm{~A}$ & $0 / 56$ \\
\hline Stage 2B & $2 / 56(3.6)$ \\
\hline Stage $3 \mathrm{~A}$ & $2 / 56(3.6)$ \\
\hline \multicolumn{2}{|l|}{ Final pathological staging (\%) } \\
\hline Stage $1 \mathrm{~A}$ & $33 / 59(55.9)$ \\
\hline Stage 1B & $14 / 59(23.7)$ \\
\hline Stage $2 \mathrm{~A}$ & $6 / 59(10.2)$ \\
\hline Stage 2B & 6/59 (10.2) \\
\hline Upstaged after pathological staging (\%) & $13 / 56(23.2)$ \\
\hline Nodal & $9 / 56(16.1)$ \\
\hline Tumour size & $4 / 56(7.1)$ \\
\hline EGFR + & $14 / 30(46.7)$ \\
\hline \multicolumn{2}{|l|}{ Tumour grade (\%) } \\
\hline Well & $14 / 49(28.6)$ \\
\hline Moderate & $23 / 49(46.9)$ \\
\hline Poor & $12 / 49(24.5)$ \\
\hline
\end{tabular}

lobectomy where abnormal vessels were encountered during hilar dissection which crossed over the left lower lobe vessels to supply the left upper lobe. This required a vascular 
sleeve. The necessary minimally invasive instruments were not available for use at that time. Conversion case three was a right lower lobectomy where pulmonary artery haemorrhage occurred during dissection but it was safely controlled by applying pressure with a sponge stick.

Table 3 Operative characteristics

\begin{tabular}{|c|c|}
\hline Characteristics & $\mathrm{N}=59$ \\
\hline Operative time, median [range] (min) & $155[80-313]$ \\
\hline \multicolumn{2}{|l|}{ Blood loss } \\
\hline Insignificant (<50 mL) & $43(72.9)$ \\
\hline $100 \mathrm{~mL}$ & $8(13.6)$ \\
\hline $200 \mathrm{~mL}$ & $4(6.8)$ \\
\hline $200-300 \mathrm{~mL}$ & $4(6.8)$ \\
\hline Conversions & $8(13.6)$ \\
\hline $\begin{array}{l}\text { Intensive care/high dependency unit duration, } \\
\text { median [range] (days) }\end{array}$ & $1[0-4]$ \\
\hline Chest tube duration, median [range] (days) & $2[1-20]$ \\
\hline Length of hospital stay, median [range] (days) & $4[2-30]$ \\
\hline Readmission & $3(5.1)$ \\
\hline Re-intervention (chest tube insertion) & $1(1.7)$ \\
\hline 30-day mortality & $0(0)$ \\
\hline Complications & $15(25.4)$ \\
\hline Prolonged chest tube (>7 days) & $8(13.6)$ \\
\hline Atrial fibrillation & $2(3.4)$ \\
\hline Haemothorax & $1(1.7)$ \\
\hline Acute kidney injury & $1(1.7)$ \\
\hline Delirium & $1(1.7)$ \\
\hline Bleeding gastrointestinal tract & $1(1.7)$ \\
\hline Subglottis oedema & $1(1.7)$ \\
\hline Acute urinary retention & $1(1.7)$ \\
\hline
\end{tabular}

Conversion case four was a right middle lobectomy where the tumour was adherent to the pericardium and right middle lobe hilar structures. Conversion case five was a left upper lobectomy with aberrant anatomy of the hilar vessels that threatened safe transection of the left upper lobe vessels. Another 2 cases were converted to open surgery due to robot technical difficulties of failure of eye vision. The other remaining case had dense adhesions and fragile tissues. To summarise, reasons for conversion included aberrant vascular and hilar anatomy, non-progression of the case, pulmonary artery haemorrhage and robot technical difficulties.

Overall, 98.2\% achieved R0 resection. One patient had positive parenchymal margins on final histopathology. Median tumour size on CT thorax was $2.65 \mathrm{~cm}(1-4.6 \mathrm{~cm})$. Median tumour size on histology was $2.5 \mathrm{~cm}(0.9-7 \mathrm{~cm})$. Histological type was predominately adenocarcinoma $86.4 \%$, followed by squamous cell carcinoma $11.9 \%$ and adenosquamous carcinoma $1.7 \%$. Pre-operative clinical staging was Stage 1A 67.9\%, Stage 1B 23.2\%, Stage 2A $0 \%$, Stage 2B 3.6\% and Stage 3A 3.6\%. Final pathological staging was Stage 1A 55.9\%, Stage 1B 23.7\%, Stage 2A $10.2 \%$ and Stage 2B 10.2\%. In comparison, $23.2 \%(\mathrm{~N}=13)$ were upstaged following pathological staging. Nodal upstaging was $16.1 \%(\mathrm{~N}=9)$, while tumour size upstaging was $7.1 \%(\mathrm{~N}=4)$.

Median follow-up was 33 months (range, 3-70 months). The mid-term results are summarised in Table 4 and Figures 1-4. The 3-year overall survival and recurrencefree survival were $86.2 \%$ (95\% CI, 72.0-96.8) and 69\% (95\% CI, 56.1-81.9) respectively. The 3-year stage-specific overall survival and recurrence free survival for stage I patients were $88.4 \%$ (95\% CI, 77.4-99.4) and 75.6\% (95\% CI, 62.3-88.9) respectively.

\section{Discussion}

The true value of an oncological resection lies in the intent

Table 4 Mid-term results

\begin{tabular}{llll}
\hline Results & 1-year $(95 \% \mathrm{Cl})$ & 2-year (95\% Cl) & 3-year (95\% Cl) \\
\hline Stage I survival & $97.8(93.5-100)$ & $95.3(88.8-100)$ & $88.4(77.4-99.4)$ \\
Stage I recurrence free survival & $91.1(82.9-99.3)$ & $81.1(69.1-93.2)$ & $75.6(62.3-88.9)$ \\
Overall survival \% & $99.5(91.6-100)$ & $94.5(88.4-100)$ & $86.2(72.0-96.8)$ \\
Overall recurrence free survival \% & $85.9(76.9-94.9)$ & $78.0(66.8-89.2)$ & $69.0(56.1-81.9)$ \\
\hline
\end{tabular}




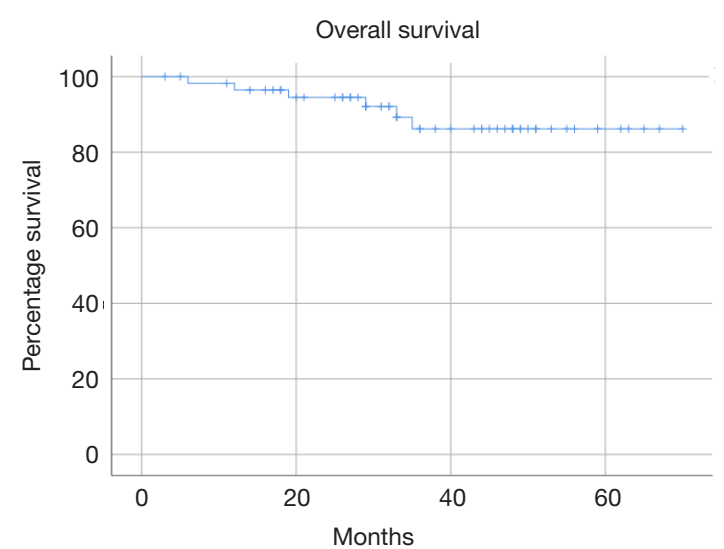

Figure 1 Overall survival for Stage I\&II NSCLC after CPRL4. NSCLC, non-small cell lung cancer.

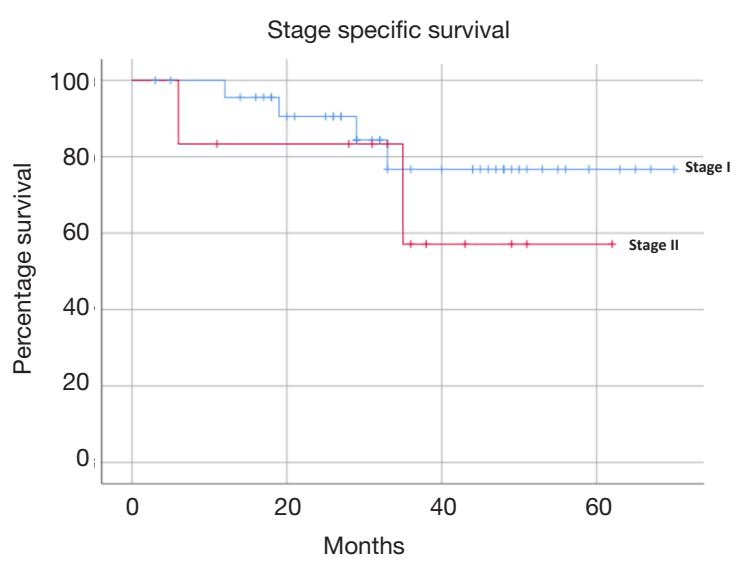

Figure 2 Stage-specific overall survival for Stage I\&II NSCLC after CPRL4. NSCLC, non-small cell lung cancer.

for cure and quality of life, whilst balancing the cost and downtime to the patient. Numerous studies in the literature have demonstrated reassuring results of the utility of roboticassisted lobectomy for primary lung cancer $(6,7,10,11)$. Cerfolio and colleagues published the largest multicentre series of 1,339 patients who underwent robotic lobectomy for primary lung cancer. They reported median operative time 136 minutes, $9 \%$ conversion rate, median hospital stay of 3 days (7). $8 \%$ experienced major complications, $16 \%$ minor complications with a $0.2 \% 30$-day mortality. The 5 -year stage-specific survival for patients with stage I\&II NSCLC ranged from $68 \%$ to $83 \%$. Another large series of robotic-assisted lobectomy for early stage NSCLC by Park and colleague that showed 3-year overall survival rates of Stage IA 97\% (95\% CI, 94-100), Stage IB 88\% (95\%

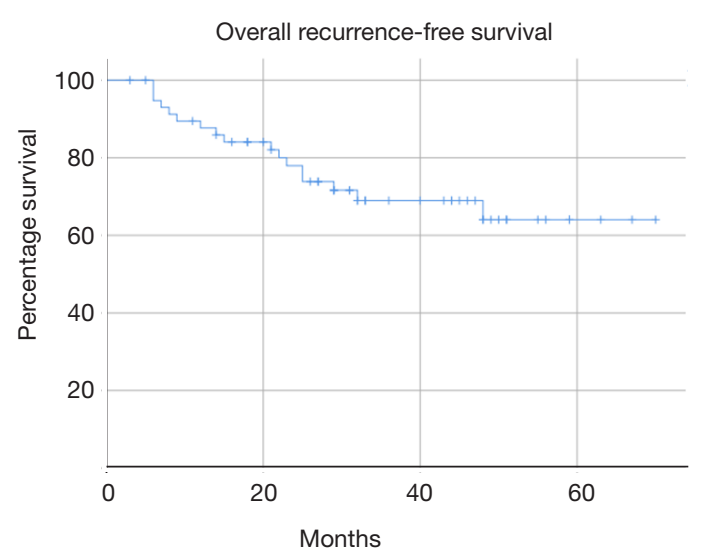

Figure 3 Recurrence-free survival for Stage I\&II NSCLC after CPRL4. NSCLC, non-small cell lung cancer.

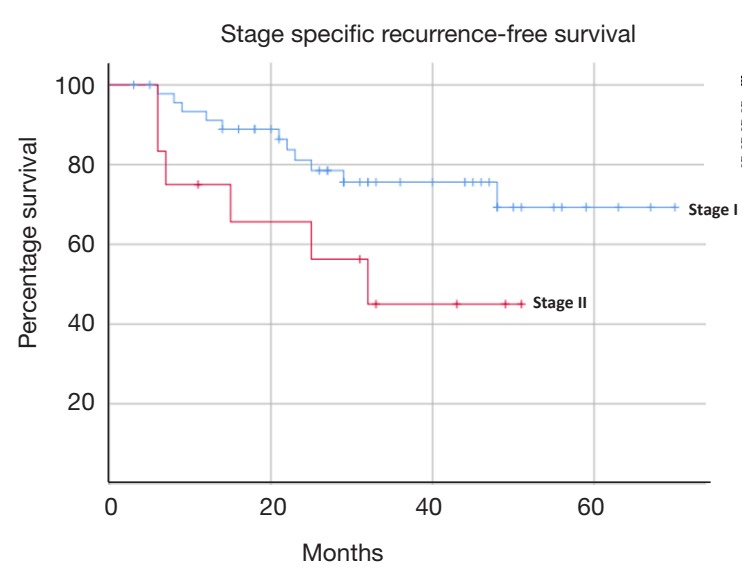

Figure 4 Stage-specific recurrence-free survival for Stage I\&II NSCLC after CPRL4. NSCLC, non-small cell lung cancer.

CI, 77-98), Stage II 72\% (95\% CI, 56-88) (6). Comparing VATS and robotic-assisted lobectomy for NSCLC, a multicentre meta-analysis concluded that there were no significant differences in peri-operative morbidity and mortality in both groups (11). In a similar vein, Lee and colleagues reported $15.2 \%$ and $13.2 \%$ nodal upstaging in patients with clinically N0 NSCLC for the VATS and robotic-assisted approach respectively (10). Despite inclusion of the learning curve, key quality outcome indicators in this study such as operative time, conversion rate, length of hospital stay, complication rate, operative mortality, nodal upstaging rate and midterm overall survival were comparable to other studies in the literature $(6,7,9,10)$.

Fortunately, the learning curve for the robotic-assisted approach is less steep in contrast to VATS (11). In addition, 
it has been demonstrated that training of surgical residents to perform robotic-assisted lobectomy whilst maintaining high quality outcomes was feasible (12). In this series, to bridge this learning curve, we set out to create protocols and training for the entire robotic surgery team. This involved multiple bi-monthly dry runs of docking and operating the robot with the aid of a simple laparoscopic training manikin and response to common critical intraoperative situations such as bleeding and non-progression of the case. Subsequently, we sought to adopt the use of the robotic-assisted approach in mediastinal operations and pulmonary wedge resections prior to embarking on the anatomical lobectomy. In our entire consecutive series of robotic lobectomy for primary lung cancer, there were 6 patients who were pre-operative clinical stage $3 \mathrm{~A}$ and 4 patient stage 4 (Oligo-metastasis) there were not included in this study. These would be considered as locally advanced resectable lung cancer and they will be analysed separately in another paper. Also, 2 patients were not offered the robotic assisted approach. One patient had cost issues while another had extensive hilar fibrosis post neoadjuvant chemoimmunotherapy. Nevertheless, cost is a major concern. Studies revealed that robotic cases cost at least $\$ 3,000$ USD more than VATS $(13,14)$, largely owing to the longer operating time and robotic supplies. It costs approximately $\$ 100 \mathrm{~K}-170 \mathrm{~K}$ USD annually to maintain the robot (11).

There are a number of limitations in this study. The retrospective nature of the study is invariably subjected to selection bias. As the sample size is small, type 2 error is pronounced. Other important measurables such as pain score, functional status, lung function, cost effectiveness and long-term survival and recurrence will be analysed in future papers.

By clearly defining CRPL4, setting guidelines and following strict algorithms, it is possible to delivery promising perioperative and mid-term outcomes for early stage NSCLC, even in a geographical location that has yet to assimilate this technology.

\section{Acknowledgments}

Shen Liang for assistance with statistical analysis.

Funding: None.

\section{Footnote}

Reporting Checklist: The authors have completed the
STROBE reporting checklist. Available at http://dx.doi. org/10.21037/jtd-20-1915

Data Sharing Statement: Available at http://dx.doi. org/10.21037/jtd-20-1915

Conflicts of Interest: All authors have completed the ICMJE uniform disclosure form (available at http://dx.doi. org/10.21037/jtd-20-1915). The authors have no conflicts of interest to declare.

Ethical Statement: All authors are accountable for all aspects of the work (if applied, including full data access, integrity of the data and the accuracy of the data analysis) in ensuring that questions related to the accuracy or integrity of any part of the work are appropriately investigated and resolved. The study was conducted in accordance with the Declaration of Helsinki (as revised in 2013). This study was approved by the Domain Specific Review Board National Health Care Group (Singapore), with waiver of patient consent (Study Reference Number 2017/00762).

Open Access Statement: This is an Open Access article distributed in accordance with the Creative Commons Attribution-NonCommercial-NoDerivs 4.0 International License (CC BY-NC-ND 4.0), which permits the noncommercial replication and distribution of the article with the strict proviso that no changes or edits are made and the original work is properly cited (including links to both the formal publication through the relevant DOI and the license). See: https://creativecommons.org/licenses/by-nc-nd/4.0/.

\section{References}

1. Postmus PE, Kerr KM, Oudkerk M, et al. Early and locally advanced non-small-cell lung cancer (NSCLC): ESMO Clinical Practice Guidelines for diagnosis, treatment and follow-up. Ann Oncol 2017;28:iv1-iv21.

2. Park BJ. Robotic lobectomy for non-small cell lung cancer: long-term oncologic results. Thorac Surg Clin 2014;24:157-62, vi.

3. Louie BE, Wilson JL, Kim S, et al. Comparison of VideoAssisted Thoracoscopic Surgery and Robotic Approaches for Clinical Stage I and Stage II Non-Small Cell Lung Cancer Using The Society of Thoracic Surgeons Database. Ann Thorac Surg 2016;102:917-24.

4. Blasberg JD, Seder CW, Leverson G, et al. Video-Assisted Thoracoscopic Lobectomy for Lung Cancer: Current 
Practice Patterns and Predictors of Adoption. Ann Thorac Surg 2016;102:1854-62.

5. Melfi FM, Menconi GF, Mariani AM, et al. Early experience with robotic technology for thoracoscopic surgery. Eur J Cardiothorac Surg 2002;21:864-8.

6. Park BJ, Melfi F, Mussi A, et al. Robotic lobectomy for non-small cell lung cancer (NSCLC): long-term oncologic results. J Thorac Cardiovasc Surg 2012;143:383-9.

7. Cerfolio RJ, Ghanim AF, Dylewski M, et al. The longterm survival of robotic lobectomy for non-small cell lung cancer: A multi-institutional study. J Thorac Cardiovasc Surg 2018;155:778-86.

8. Edge S, Byrd DR, Comptom CC, et al. editors. AJCC cancer staging handbook: from the AJCC cancer staging manual. 7th edition. New York: Springer; 2009.

9. Cerfolio RJ. Total port approach for robotic lobectomy. Thorac Surg Clin 2014;24:151-6, v.

10. Lee BE, Shapiro M, Rutledge JR, et al. Nodal Upstaging

Cite this article as: Ong K, Fazuludeen AA, Ahmed ADB. Mid-term results of completely portal robotic lobectomy for stage I \& II non-small cell lung cancer. J Thorac Dis 2020;12(10):5369-5375. doi: 10.21037/jtd-20-1915 in Robotic and Video Assisted Thoracic Surgery Lobectomy for Clinical N0 Lung Cancer. Ann Thorac Surg 2015;100:229-33; discussion 233-4.

11. Wei S, Chen M, Chen N, et al. Feasibility and safety of robot-assisted thoracic surgery for lung lobectomy in patients with non-small cell lung cancer: a systematic review and meta-analysis. World J Surg Oncol 2017;15:98.

12. Cerfolio RJ, Cichos KH, Wei B, et al. Robotic lobectomy can be taught while maintaining quality patient outcomes. J Thorac Cardiovasc Surg 2016;152:991-7.

13. Deen SA, Wilson JL, Wilshire CL, et al. Defining the cost of care for lobectomy and segmentectomy: a comparison of open, video-assisted thoracoscopic, and robotic approaches. Ann Thorac Surg 2014;97:1000-7.

14. Park BJ, Flores RM. Cost comparison of robotic, videoassisted thoracic surgery and thoracotomy approaches to pulmonary lobectomy. Thorac Surg Clin 2008;18:297300, vii. 